This document was prepared in conjunction with work accomplished under Contract No. DE-AC09-96SR18500 with the U. S. Department of Energy.

\title{
DISCLAIMER
}

This report was prepared as an account of work sponsored by an agency of the United States Government. Neither the United States Government nor any agency thereof, nor any of their employees, nor any of their contractors, subcontractors or their employees, makes any warranty, express or implied, or assumes any legal liability or responsibility for the accuracy, completeness, or any third party's use or the results of such use of any information, apparatus, product, or process disclosed, or represents that its use would not infringe privately owned rights. Reference herein to any specific commercial product, process, or service by trade name, trademark, manufacturer, or otherwise, does not necessarily constitute or imply its endorsement, recommendation, or favoring by the United States Government or any agency thereof or its contractors or subcontractors. The views and opinions of authors expressed herein do not necessarily state or reflect those of the United States Government or any agency thereof. 


\section{Cross-flow Ultrafiltration Scaling Considerations}

by

MARK DUIGNAN

Westinghouse Savannah River Company

Savannah River Site

Aiken, South Carolina 29808

Additional Authors:

SI LEE

SI

DOE Contract No. DE-AC09-96SR18500

This paper was prepared in connection with work done under the above contract number with the U. S. Department of Energy. By acceptance of this paper, the publisher and/or recipient acknowledges the U. S. Government's right to retain a nonexclusive, royalty-free license in and to any copyright covering this paper, along with the right to reproduce and to authorize others to reproduce all or part of the copyrighted paper. 


\title{
FEDSM2006-98492
}

\section{CROSS-FLOW ULTRAFILTRATION SCALING CONSIDERATIONS}

\author{
Mark R. Duignan* and Si Y. Lee \\ Savannah River National Laboratory \\ Aiken, SC 29808 \\ *mark.duignan@srnl.doe.gov \\ *(803)725-8256
}

\begin{abstract}
One legacy of the nuclear age is radioactive waste and it must be stabilized to be stored in a safe manner. An important part of the stabilization process is the separation of radioactive solids from the liquid wastes by cross-flow ultrafiltration. The performance of this technology with the wastes to be treated was unknown and, therefore, had to be obtained. However, before beginning a filter study the question of experimental scale had to be addressed. Of course, carrying out experiments using full-size equipment is always ideal, but rarely practical when dealing with plant size processes. Flow loops that will handle millions of liters of slurries, which are either highly caustic or acidic, with flow rates of 10,000 lpm make full-scale tests prohibitively expensive. Moreover, when the slurries happen to be radioactive such work is also very dangerous. All of these considerations lend themselves to investigations at smaller scales and in many situations can be treated with computational analyses. Unfortunately, as scale is reduced it becomes harder to provide prototypic results and the two and three phase multi-component mixtures challenge accurate computational results.
\end{abstract}

To obtain accurate and representative filter results the use of two scales were chosen: 1 . Small-scale - would allow the testing with actual radioactive waste samples and compare results with simulated wastes that were not radioactive. For this scale the feed tank held 6 liters of waste and it had a single cross-flow filter tube $0.61 \mathrm{~m}$ long. 2. Pilot-scale - would be restricted to use simulated non-radioactive wastes. At this larger scale the feed tank held 120 liters of waste and the filter unit was prototypic to the planned plant facility in pore size (0.1 micron), length $(2.29 \mathrm{~m})$, diameter $(0.0127 \mathrm{~m}$ inside and $0.0159 \mathrm{~m}$ outside diameter), and being multi-tubed.

The small-scale apparatus is convenient, easy to use, and can test both radioactive and non-radioactive wastes; therefore, there is a larger database than at the pilot scale. In fact, the small-scale data are very useful to compare actual waste to simulated waste filter performance to validate a simulant, but data availability does not mean they accurately represent fullscale performance. Results indicate that small-scale filter fluxes to be significantly higher that those at the pilot scale. In an attempt to study the difference in filter performance at the two scales an experiment was done that used exactly the same simultant which was created at the same time so that issues of composition and aging would not compromise the results. This paper will discuss those experimental results, as well as those from a computational fluid dynamics model to better understand the small-scale limitations.

Keywords: Small-scale, Pilot-scale, Radioactive Waste, TwoPhase Flow

\section{INTRODUCTION}

One of the principal steps in pretreating radioactive waste in the complex process of putting it into a safe stabilized form is the separation and concentration of undissolved solids. Today there exist many technologies for separation and concentration, however, when faced with a waste that is highly radioactive, strongly caustic, strongly acidic, to name a few of its challenging attributes, then the options are limited. However, "...despite the formidable problems, modern filtration continues to produce separations in seemingly intractable situations...[1: p. 1].” One filtration technology that has been shown to work is cross-flow filtration. Thick wall $(\sim 0.002 \mathrm{~m})$ metal cross-flow filters have the advantage of being passive, i.e., no moving parts to wear out fast, and cross-flow action maintains the filter cake thin, so that it can operate for very long periods as opposed to dead-end filter that must be replaced when its cake presents a prohibitively large pressure drop. While no technology is maintenance free, cross-flow filters minimizes the number of exposure hours to plant personnel 
needed for cleaning or replacement; therefore, it is an excellent choice for radioactive waste treatment. For a planned Waste \& Immobilization Treatment Plant (WTP), which will have particulates to below a micron, then Low-Shear Cross-flow Ultrafiltration has been found to work well [2: pp. 6-7].

One fundamental aspect of designing the WTP is to have a good understanding of the performance of each of the included technologies so the product throughput can be estimated. One of the main challenges to this understanding is the very large variety of radioactive wastes. This variety includes thousands of chemical compositions, levels of radioactivity, types of liquids, e.g., organic or not, and forms of solids. Another challenge is simply the amount of waste to be treated, i.e., literally millions of liters. Determining performance at full scale will give the best results but for the size plant needed and type waste to be handled the cost is prohibitive. Smaller scale test facilities and computational modeling are useful tools in evaluating filter operation, but each has its limitations.

In 1997 cross-flow filtration was considered, "a semiempirical science," due to "the complex combination of hydrodynamic, electrostatic and thermodynamic forces that effect flux and/or retention," [3: p. 273]. In 2006 it still is. Computational fluid dynamics (CFD) is useful to study specific aspects of cross-flow filtration but it also will not give accurate results without it being benchmarked to a database of experimental results. Moreover, for experimental results from scaled test facilities it is very important to understand what is compromised as size shrinks. The inverse of this problem is scale-up and "there is lack of published information on scaleup...one problem is that there are too many variables" [4].

It is inappropriate to take small scale results and simply scale them up to full scale. The process must be taken in steps [5]; therefore, a compromise was used for the WTP: small scale for radioactive waste and pilot scale for simulated waste. The movement and testing of actual radioactive waste is expensive and dangerous. This requires considerable caution and naturally its use is limited to the smallest amounts necessary to obtain accurate results. With this in mind a smallscale cross-flow filter was designed to safely filter small quantities ( 1 to 6 liters) of actual waste. Then a "cold" simulant would be made and tested in another same-scale filter to verify that it produced the same filter performance. As such, the simulant could be chemically modified until its filter performance matched that of the actual waste. This fine tuning is important because the slurries are very complex, e.g., even changing something as subtle as the shape of the solid particles affects slurry viscosity [6: p. 65], which in turn affects filtration both mechanically and hydrodynamically. This "side-by-side" comparison made the small-scale filter an excellent tool to obtain a representative simulated waste.

With a recipe for simulated waste in hand then large quantities could be made to test at a larger scale. At full scale the quantity would be too large, but a pilot scale allowed the best compromise of a near prototypic test facility, explained later, while using reasonable quantities of simulant, e.g., 1000 liters. However, even the simulants were very expensive because of the chemical complexities, which limited the different types of wastes to be tested at the pilot scale.

Since the small-scale cross-flow ultrafiltration facility is able to test both radioactively hot and cold wastes, as well as only needing a small amount of waste to test, its filter performance database is considerably larger than that of the pilot-scale facility. This availability makes it tempting to use the small-scale results for aspects of the design for full-scale operation. When comparing water fluxes at both scales it appeared that the small scale always seemed to give better filter performance. As such, small-scale results would not be conservative for the design of WTP. However, since water does not have solids to challenge the filters those results were not appropriate to judge performance. Furthermore, through years of testing with different wastes at both scales there were, at least, qualitative indications that the small-scale filter performance was indeed better and thus did not represent fullscale operation. Unfortunately, there was never a test planned to verify the difference in performance since scaling up smallscale results was not initially considered. It is important to note that to make an accurate comparison a test would have to be planned. As already mentioned, the wastes, and thereby their simulants are complex and each batch is slightly different. Even taking samples from the same batch become different with time due to aging.

To answer the question of how small-scale and pilot-scale filter performance results compare a test was planned to filter the same batch of simulant under the same conditions at the same time. This paper discusses those results.

\section{NOMENCLATURE}

$\begin{array}{ll}{ }^{\circ} \mathrm{C} & \text { Degree Centigrade (or Celsius) } \\ \mathrm{cP} & \text { Centipoise } \\ \mathrm{CFD} & \text { Computational Fluid Dynamics } \\ \mathrm{D} & \text { Diameter } \\ \mathrm{DOE} & \text { U.S. Department of Energy } \\ \mathrm{hr} & \text { Hour } \\ \mathrm{kg} & \text { Kilogram } \\ \mathrm{L} & \text { Liter } \\ \mathrm{lpm} & \text { Liter per minute } \\ \mathrm{m} & \text { Meter } \\ \mathbf{M} & \text { Molar (Table 2) } \\ \mathrm{mg} & \text { Milligram } \\ \mathrm{min} & \text { Minute } \\ \mathrm{mL} & \text { Milliliter } \\ \mathrm{mPa} \cdot \mathrm{s} & \text { MilliPascal Second } \\ \mathrm{Pa} & \text { Pascal } \\ \mathrm{PSD} & \text { Particle Size Distribution } \\ \mathrm{s} & \text { Second }\end{array}$


TMP Transmembrane Pressure (the average pressure drop across the thickness of the filter medium perpendicular to the slurry flow.)

\section{UDS Undissolved Solids}

$\mathrm{V} \quad$ Velocity of the slurry flow along the length of the filter tubes

WSRC Washington Savannah River Company

WTP Waste \& Immobilization Treatment Plant

YS Yield Stress $(\mathrm{Pa})$

\section{TEST EQUIPMENT}

For brevity the details for the small-scale equipment [7, 8, 9] and the pilot-scale equipment $[10,11,12]$ are well documented and will not be repeated. However, highlights for both test facilities are described to appreciate the difference in scale. Table 1 shows a side-by-side comparison of the facilities and how they compare to the planned full-size WTP.

Table 1. Comparison of full-scale to scaled test facilities

\begin{tabular}{|c|c|c|c|}
\hline Comparison & Planned WTP & Pilot Scale & Small Scale \\
\hline Material & 316 L stainless steel & same & same \\
\hline Porous Structure & sintered & same & same \\
\hline Average Pore Size & 0.1 micron & same & same \\
\hline Length & 2.29 meters & same & $0.61 \mathrm{~meter}$ \\
\hline Tube Inside Diameter & $0.0127 \mathrm{~m}$ & same & $0.0095 \mathrm{~m}$ \\
\hline Tube Outside Diameter & $0.0159 \mathrm{~m}$ & same & $0.0127 \mathrm{~m}$ \\
\hline Filter Area per Tube & $0.0912 \mathrm{~m}^{2}$ & same & $0.0182 \mathrm{~m}^{2}$ \\
\hline Arrangement & multiple & same & single \\
\hline Number & 243 per bundle & 7 & 1 \\
\hline Grid Pattern & $60^{\circ}$ Triangular & same & not applicable \\
\hline Center-to-Center Distance & $0.0222 \mathrm{~m}$ & same & not applicable \\
\hline Orientation & Horizontal & Vertical & Horizontal \\
\hline Other Features & \multicolumn{4}{|l}{} \\
\hline Slurry Pump & centrifugal & same & low shear \\
\hline
\end{tabular}

† Orientation is included in the scaled criteria for completeness; however, it is not considered a significant difference during slurry flow because of turbulence. However, orientation would be important during shut down when gravity can assist emptying vertical tubes.

Of course, the principal piece of hardware of each of the facilities is the porous filter itself and the flow loops through which the waste circulates. Table 1 shows that the pilot-scale filter matches the full-scale unit in almost all aspects except that instead of containing 243 tubes in parallel there are only 7 in parallel, Figs. 1 and 2. However, the 7-tube filter was expected to function the same in that the pressure boundary is such that all of the tubes are inter-dependent. One other difference is the filter-tube orientation, which during operation is not significant. That is, operating under planned pressures and waste velocities the flow regime will be turbulent within each of the porous tube. Orientation is important for filter shut down and startup, but that is beyond the current scope of work.

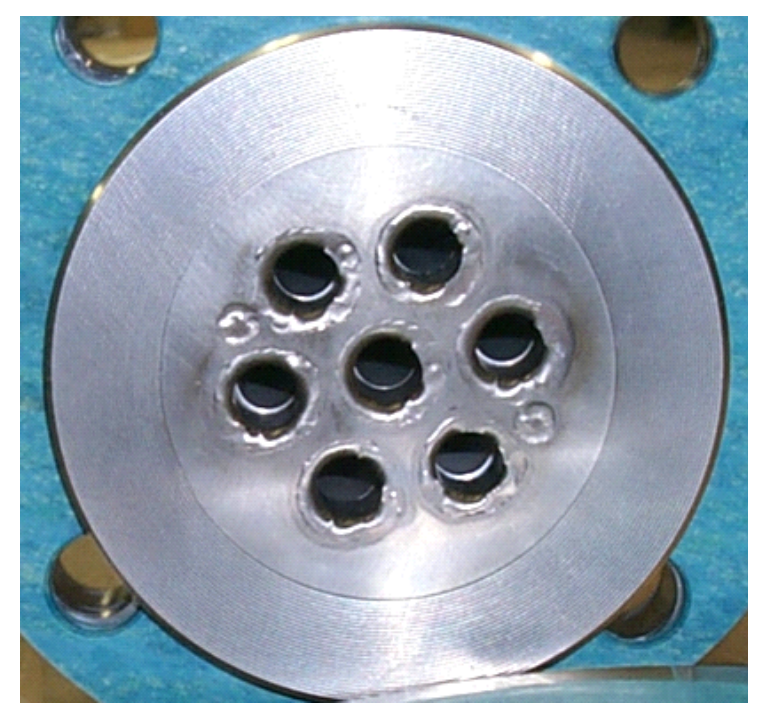

Figure 1. Tube sheet for pilot-scale filter unit

A close look at Fig. 2 shows that each of the seven porous tubes was made of four sections welded together. This is because the longest contiguous tube manufactured was $0.61 \mathrm{~m}$ (24 inches); therefore, the needed length of $2.29 \mathrm{~m}$ was made by joining four sections, each $0.572 \mathrm{~m}$ long. The small-scale unit used one section of tube, $0.61 \mathrm{~m}$ in length.

As already stated, the purpose of the small-scale facility was two-fold: 1. Test actual waste filterability, which is radioactively hot, and 2 . compare those filter performance results to the filterability of a simulant of that waste. The pilotscale test rig was designed to be close to prototypic to minimize scaling issues so that confident full-scale data could be obtained. Of course, the drawback of the larger pilot scale is the amount of waste it needs and that it has to operate radioactively cold. This means a simulant must be used.

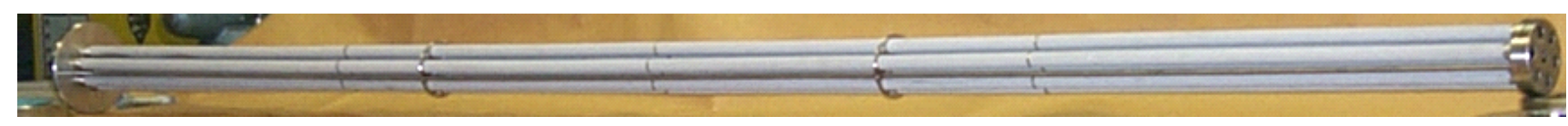

Figure 2. The 2.29-m long seven-tube pilot scale filter unit outside of its housing 


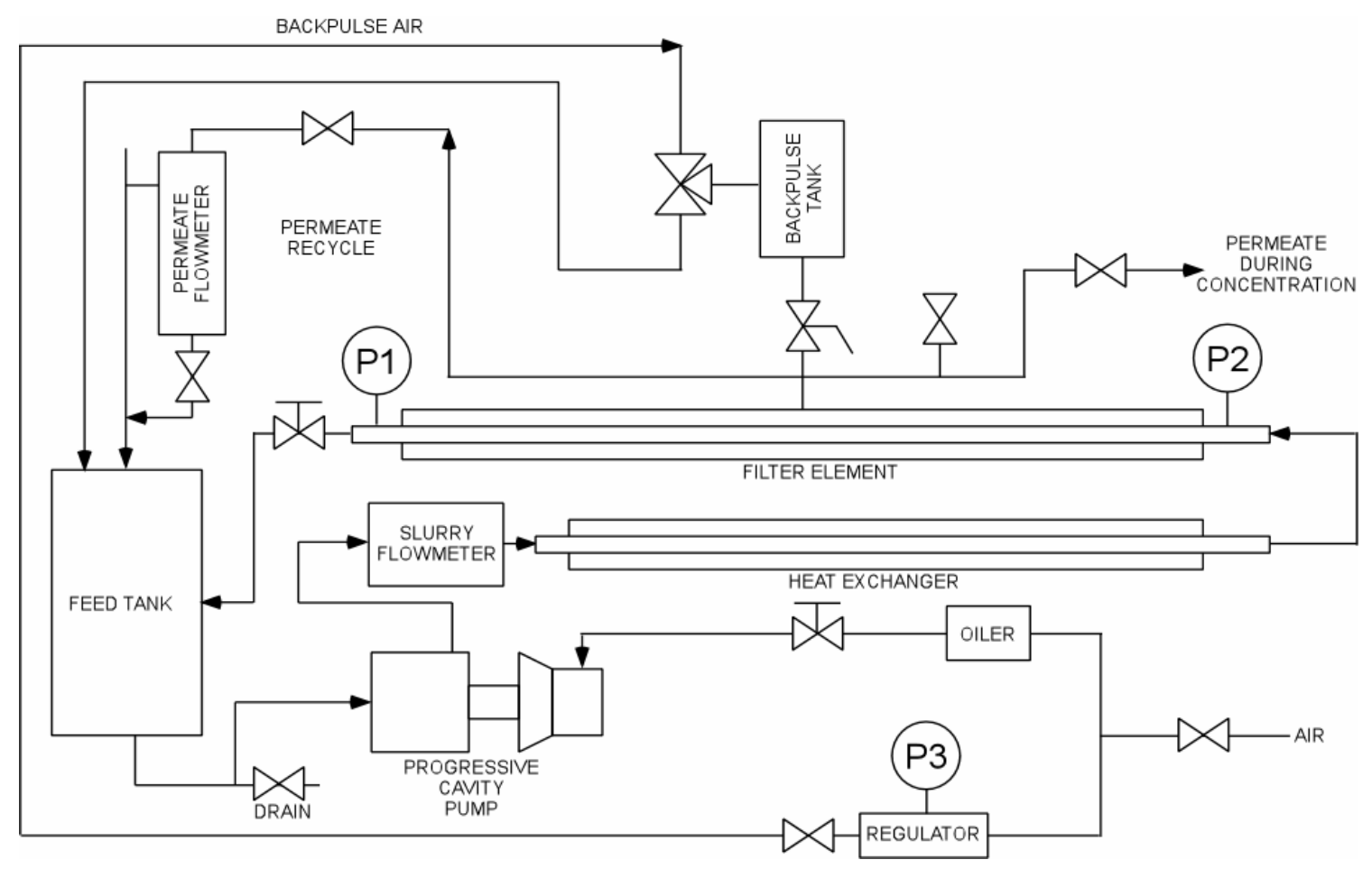

Figure 3. Small-scale cross-flow filter

Figure 3 is a schematic of the small-scale test rig and the filter is approximately in the center. Figure 5 shows the pilotscale facility and for convenience the filter is also shown in the center with porous tubes in parallel, but refer to Fig. 1 to see the actual tube-to-tube orientation. Outside of size, the two units have many similarities, which are discussed below.

Slurry loop - This is the loop that contains the filter and its housing and serves as the primary flow path for circulating slurries. It begins at the slurry feed tank and then moves through the pump, heat exchanger, the filter, control valve, and then returns to complete the circuit. The small-scale unit cools the slurry before entering the filter and the cooling for the pilot-scale unit follows the filter. Also included are the appropriate sensors to make flow, pressure, and temperature measurements. For the filter itself the small-scale contains a single 0.1 micron porous tube and the pilot unit contains seven tubes in parallel, which are welded in a $60^{\circ}$ triangular pitch geometry with a center-to-center pitch distance of $0.022 \mathrm{~m}$, Fig. 1, to match the tube-sheet grid of the plant filters.

Permeate loop - This loop (the permeate recycle for the small scale and the permeate lines for the pilot scale) begins at the filter housing where the permeate is separated from the slurry, Fig 4.

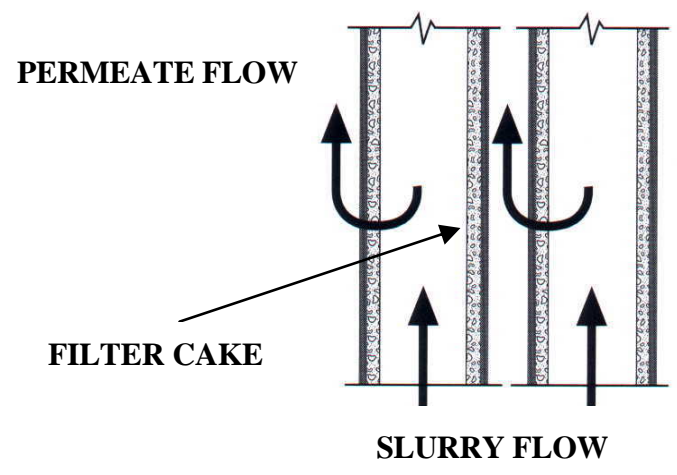

Figure 4. Operation of a multi-tube cross flow filter

From the housing the loop directs the permeate to flow through the backpulse tank (or pulse pot) before removed for further processing, as will occur in the actual plant. However, for the laboratory tests the permeate can also be returned to the filter feed tank and remixed into the slurry. This would be done when data are obtained at a constant slurry concentration in order to measure different operational parameters. For this scale comparison test the permeate was not returned so as to allow the slurry to concentrate and mimic actual plant operation. 


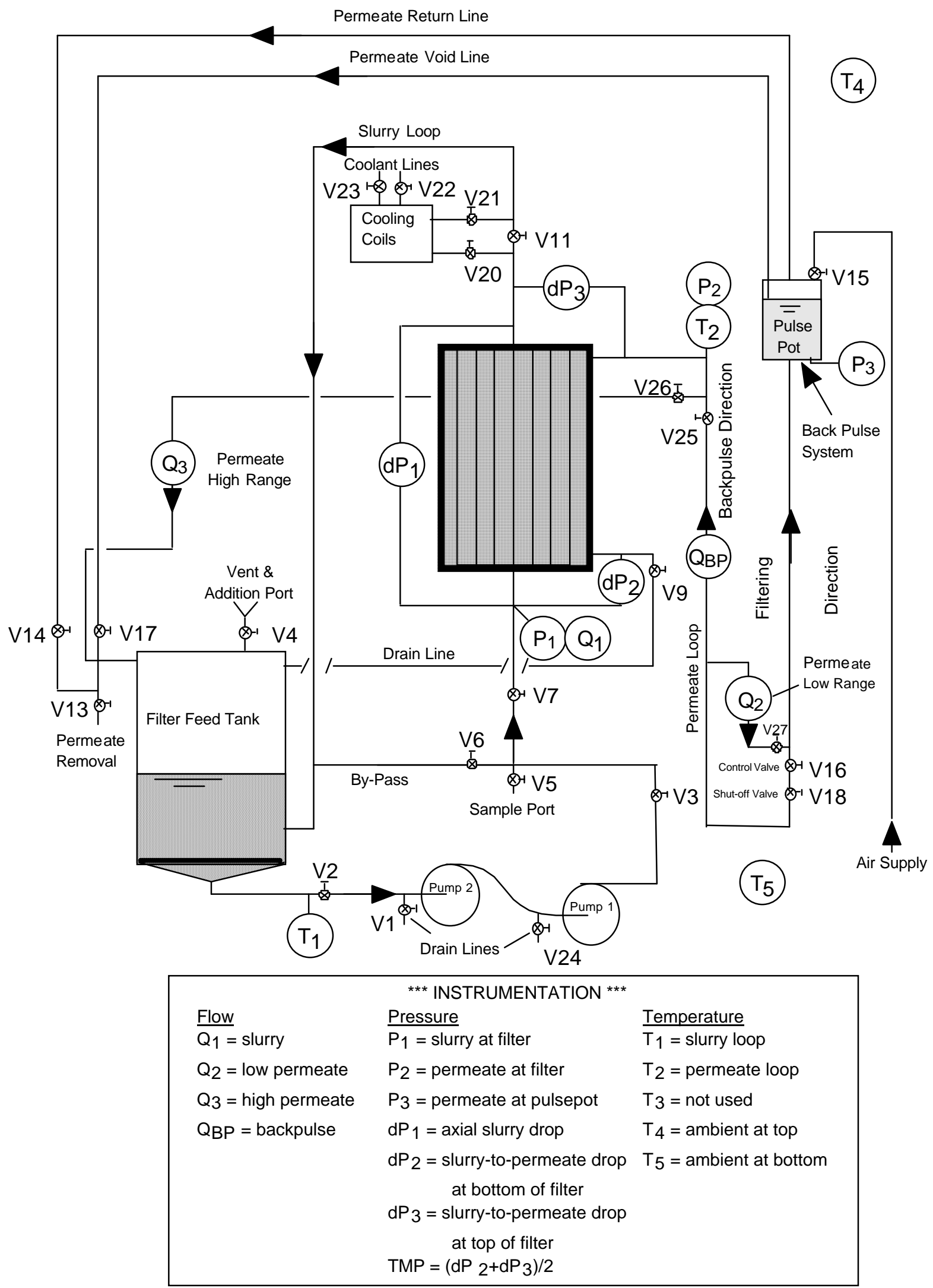

Figure 5. Pilot-scale cross-flow filter 
The pulse pot is a device which can reverse the flow of the permeate back through the filter to clean the porous wall of built-up filter cake. This is normally done when the transmembrane pressure becomes large or the permeate flowrate drops to an unacceptable level. Backpulsing was not used for this test since the purpose was to show steady state filter fluxes.

\section{SIMULANT}

Besides differences in scale of the two facilities, the other important parameter to consider, and maintain constant, is the chemical stability of the simulant. The complex slurry wastes to be processed through the WTP [13] make filter performance comparisons very difficult because no two batches of slurry waste simulant are the same. Even when following the same recipe the resulting slurry may not be the same due to differences of how the recipe is applied and subsequent aging before filtration begins, etc. The measured chemical composition, shown in Table 2, is from the simulant developed for this test [14] and it matches actual waste, within measurement uncertainty ${ }^{\dagger}$. In making the simulant forty-seven compounds were used with sodium gluconate being the organic complexant. To try to create exactly the same product by making two different batches, which also include a series of precipitation steps, would be very difficult if not impossible. Therefore, to address the issue of difference due to filtration scale, the slurry feed stock should be the same. This was met by making a single batch of simulant, separate the necessary volume for each of the two test facilities, and then begin the two tests at the same time. As is turned out the small-scale test started 16 hours after the pilot-scale test, which will be discussed later.

Table 2. Simulated Waste Composition

\begin{tabular}{|c|c||c|c||c|c|}
\hline Species & $\mathrm{mg} / \mathrm{L}$ & Species & $\mathrm{mg} / \mathrm{L}$ & Species & $\mathrm{mg} / \mathrm{L}$ \\
\hline $\mathrm{Al}$ & 9500 & $\mathrm{~W}$ & 137 & $\mathrm{NO}_{2}^{-}$ & 54500 \\
\hline $\mathrm{B}$ & 38.3 & $\mathrm{Zn}$ & 4.45 & $\mathrm{NO}_{3}^{-}$ & 137000 \\
\hline $\mathrm{Ba}$ & 0.45 & $\mathrm{Zr}$ & 8.1 & $\mathrm{Cl}^{-}$ & 3700 \\
\hline $\mathrm{Ca}$ & 407 & $\mathrm{~K}$ & 2860 & $\mathrm{~F}^{-}$ & 921 \\
\hline $\mathrm{Cd}$ & 36.2 & $\mathrm{La}$ & 24.3 & $\mathrm{PO}_{4}^{-3}$ & 1970 \\
\hline $\mathrm{Ce}$ & 28.8 & $\mathrm{Mg}$ & 1.01 & $\mathrm{SO}_{4}^{-2}$ & 10400 \\
\hline $\mathrm{Co}$ & 1.44 & $\mathrm{Mn}$ & 16.6 & formate & 7350 \\
\hline $\mathrm{Cr}$ & 156 & $\mathrm{Mo}$ & 30.7 & oxalate & 343 \\
\hline $\mathrm{Cu}$ & 7.2 & $\mathrm{Na}$ & 137000 & & $\mathrm{M}$ \\
\hline $\mathrm{Fe}$ & 30.6 & $\mathrm{Nd}$ & 40.3 & free $\mathrm{OH}^{-}$ & 0.216 \\
\hline $\mathrm{S}$ & 3380 & $\mathrm{Ni}$ & 265 & total base & 1.66 \\
\hline $\mathrm{Sr}$ & 2.94 & $\mathrm{P}$ & 696 & & \\
\hline $\mathrm{Si}$ & 40.2 & $\mathrm{~Pb}$ & 63.4 & SpG & 1.32 \\
\hline
\end{tabular}

\footnotetext{
$\dagger$ The actual waste is from DOE Hanford Site Tank 241-AN-102 and the analytical measurement uncertainty was $\pm 25 \%$ for measurements of less than $10,000 \mathrm{mg} / \mathrm{L}$ and $\pm 10 \%$ for measurements equal to and above that value.
}

\section{MEASUREMENT UNCERTAINTY}

The measurement uncertainties of test measurement equipment are listed below. The details on how the uncertainties were obtained are shown elsewhere [12]. The measurement uncertainties (at the 95\% confidence level) for the important quantities were:

Slurry Velocity $= \pm 6 \%$

Transmembrane Pressure $= \pm 2 \%$

Temperature $= \pm 2^{\circ} \mathrm{C}$

Permeate Flux $= \pm 10 \%$

Slurry or Liquid Density $= \pm 0.5 \%$

Slurry solids weight percent $= \pm 15 \%$

\section{SMALL- VS. PILOT-SCALE RESULTS}

A 1000-liter batch of simulant was made for the test. After precipitating and mixing for 4 hours at $50^{\circ} \mathrm{C}, 75$ liters of simulant were removed to be use in a small-scale facility. Figure 6 shows the comparison of the two sets of results after the simulant was concentrated at $25^{\circ} \mathrm{C}$ from $1.4 \mathrm{wt} \%$ to $19 \mathrm{wt} \%$ (for the small scale) over a 14-hour period and at $25^{\circ} \mathrm{C}$ from 1.2 wt $\%$ to $22 \mathrm{wt} \%$ (for the pilot scale) over a 12 -hour period ${ }^{\ddagger}$.

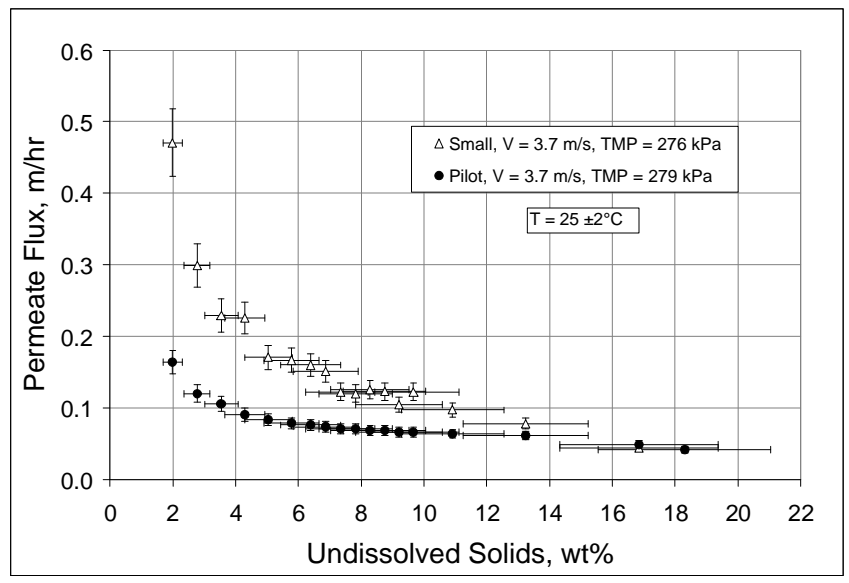

Figure 6. Small vs. pilot permeate flux

It is important to note that the permeate flux data in Fig. 6 were obtained differently for each facility. For the small-scale unit each datum point was an average of a 3-liter batch of slurry because it did not have in-line permeate flux meter. (The feed tank held 6 liters but was refilled after each 3 liters of operation.) That is, the flux was determined by measuring the time it took for 3 liters to be filtered. Further, that unit operated until the slurry solids concentration reached approximately 19 $\mathrm{wt} \%$, but the last average flux value was at approximately 17 $\mathrm{wt} \%$. For the pilot-scale unit the permeate flux was measured

\footnotetext{
* The difference in the initial small- and pilot-scale undissolved solids concentrations may be due to analytical measurements or sampling techniques. The difference in concentration periods is due to different flux rate and filter surface area.
} 
in-line instantaneously and the data were taken every minute. To make the Fig. 6 comparison the values of the pilot flux were taken at each of the averaged small-scale undissolved solids points. This is the reason why all the abscissa points line up perfectly. The pilot-scale filter concentrated up to $22 \mathrm{wt} \%$ undissolved solids; however, results above $19 \mathrm{wt} \%$ were not included because there were none from the small-scale test to compare. Note that at about $16 \mathrm{wt} \%$ undissolved solids the two curve merge. The two data sets were expected to converge at the higher solids concentrations because the filter cake becomes very thick and differences in scale become smaller. Coincidentally, at $16 \mathrm{wt} \%$ the small-scale facility was close to its operational limit.

In general, it looks like the small-scale permeate flux is about a factor of 2 larger than the pilot facility up to approximately $10 \mathrm{wt} \%$ undissolved solids, after which the curves merge. At that point the thickness of the filter cake and increased slurry consistency minimize any differences due to scale. The data obtained from both tests do not give a clear indication as to why the curves are significantly different. Table 3 includes some of the pertinent information of the facilities and the slurry used in both.

Table 3. Small vs. pilot test facts and results

\begin{tabular}{|c|c|c|}
\hline Test Facility & Pilot Scale & Small Scale \\
\hline Test Duration & 12 hours & 14 hours \\
\hline Starting Volume & 1000 liters & 75 liters \\
\hline Slurry reservoir capacity & 120 liters & 6 liters \\
\hline Flow Loop volume (without reservoir) & $\sim 34$ liters & $<0.2$ liters \\
\hline Slurry circulation rate & $193 \mathrm{lpm}(27.6 \mathrm{lpm} / \mathrm{tube})$ & $15 \mathrm{lpm}$ \\
\hline Longest residence time of slurry & 48 seconds & 25 seconds \\
\hline Slurry circulation time in flow loop & 10 seconds & 1second \\
\hline Type of circulation pumps & 2 centrifugal & 1progressive cavit \\
\hline Constant axial slurry velocity & $3.7 \mathrm{~m} / \mathrm{s}$ & $3.7 \mathrm{~m} / \mathrm{s}$ \\
\hline Constant transmembrane pressure & $279 \mathrm{kPa}$ & $276 \mathrm{kPa}$ \\
\hline \multicolumn{3}{|c|}{ Before Filtration: Slurry at Low Solids Concentration } \\
\hline Undissoved Solids & $1.2 \mathrm{wt} \%$ & $1.4 \mathrm{wt} \%$ \\
\hline Total Solids & $33 \mathrm{wt} \%$ & $33 \mathrm{wt} \%$ \\
\hline Slurry Consistency & $4.0 \mathrm{cP}$ & $4.2 \mathrm{cP}$ \\
\hline Yield Stress & $0 \mathrm{~Pa}$ & Pa \\
\hline Slurry Density & $1288 \mathrm{~kg} / \mathrm{m}^{3}$ & $1300 \mathrm{~kg} / \mathrm{m}^{3}$ \\
\hline PSD (by volume distribution): Mean & 8.6 micron $(48 \%)^{*}$ & 15 micron $^{*}$ \\
\hline PSD (by volume distribution): Mean & 2.3 micron $(52 \%)^{*}$ & 3.5 micron* \\
\hline PSD (by volume distribution):Range & $1.2-52$ micron & $0.5-75$ micron \\
\hline PSD (by number distribution): Mean & 2.0 micron & 2.5 micron \\
\hline PSD (by number distribution): Range & $1.2-19$ micron & $0.8-6$ micron \\
\hline \multicolumn{3}{|c|}{ After Filtration: Slurry at High Solids Concentration } \\
\hline Undissolved Solids & $22 \mathrm{wt} \%$ & $19 \mathrm{wt} \%$ \\
\hline Total Solids & $47 \mathrm{wt} \%$ & $46 \mathrm{wt} \%$ \\
\hline Slurry Consistency & $17 \mathrm{cP}$ & $15 \mathrm{cP}$ \\
\hline Yield Stress & $9 \mathrm{~Pa}$ & $11 \mathrm{~Pa}$ \\
\hline Slurry Density & $1430 \mathrm{~kg} / \mathrm{m}^{3}$ & $1400 \mathrm{~kg} / \mathrm{m}^{3}$ \\
\hline PSD (by volume distribution): Mean & 8.2 micron $(13 \%)^{*}$ & 6 micron $^{*}$ \\
\hline PSD (by volume distribution): Mean & 0.9 micron $(87 \%)^{*}$ & 1.5 micron" \\
\hline PSD (by volume distribution): Range & $<0.7-44$ micron & $0.3-45$ micron \\
\hline PSD_by number distribution): Mean & .-. 0.8 micron & -2micron \\
\hline PSD (by number distribution): Range & $<0.7-2$ micron & $0.8-5$ micron \\
\hline & "'bi-modal distribution & "ki-modal distribution \\
\hline
\end{tabular}

As already stated above, the starting slurries were exactly the same, taken from the same batch. The batch was made at one time and then 75 liters were separated for the small-scale test. Unfortunately, the starting time for each test turned out to be different. The pilot began filtration immediately after the freshly made simulant was ready. The small-scale test began the following day, i.e., after approximately 16 hours; therefore, further reactions could have occurred. In fact, the mean size of the solid particles in the initial simulant used for the small-scale filter appears to be slightly, but significantly, larger, which may be from measurement error. However, all other characteristics, i.e., solids concentration, rheology, and density, appear to be the same. The particle-size difference shown may have indeed existed or it may have simply been how the particle size distribution (PSD) measurement was performed. For instance, the PSD samples sit for a while before processing so they are given a mild amount of sonication to reduce the particles to their base size. The question is, "What is that base size?"

After both filtration tests the final simulant PSD show three distinct changes:

1. The mean particle size was reduced by a factor of 10 for the volume distribution and to approximately one half for the number (or population) distribution.

2. The spread of particle sizes was reduced to approximately one half.

3. The bimodal volume distribution was reduced to predominately mono-modal.

Initially the difference in filter fluxes results in Fig. 6 was thought to be due to the different pump types, i.e., low shear progressive cavity of the small scale to high shear centrifugal of the pilot scale. It is logical to assume that the higher shear pump in the pilot-scale test would more effectively cause the particles to become smaller and thus make the slurry harder to filter. In fact, the data do show that the mean particle size of the concentrated slurry for the pilot may be slightly smaller, however, the same difference in particle size is apparent in the initial slurry, Table 3. That is, the pump was not the principal cause of the difference. Chemical reaction during the extra 16 hours of waiting to start filtration at the small scale is probably a stronger factor in the size of the particles. Another fact that contradicts the size hypothesis became evident in other waste tests not part of this work. The simulant filtration data being discussed here is only a small subset of the many simulated wastes actually tested. Several similar simulants were tested with the small-scale facility. One study compared particle size versus filter flux [9]. The results showed that as the mean particle size became smaller the average filter flux increased! As it turned out, one cannot just simply look at size because particle shape is a factor, too. This counter-intuitive result was made clear from micrograph evidence that showed sheet-like flat particles in the 5 to 20 micron range for less filterable simulants. Particles of less than 5 microns did not result in flat sheets. Flat particles, or sheets of particles, seem to be more effective in covering, or blanketing, the filter surface.

As the slurry is processed in the filter facilities some of the large flat particles presumably break up through shear. This breakup can happen in both the small- and pilot-scale units. 
The fact that the small-scale unit uses a low-shear pump does not mean the slurry does not experience shear; the pump presents only one mechanism of introducing shear. By design the small-scale unit was made to minimize the amount of slurry needed to filter; radioactive slurry samples are small, expensive, and dangerous. Since the filter-tube velocity was made to be the same for both scales, the shorter flow loop and smaller volume of the small-scale unit meant a higher circulation rate. As an example for the conditions listed in Table 3, the slurry in the small-scale unit takes just under 1 second to traverse the entire loop. If the longest residence time is used, 25 seconds, which includes time the slurry sits in the feed tank, then for the first charge of 6 liters of slurry, of which 3 liters were concentrating over a 20.4-min period, the slurry circulated $20.4 * 60 / 25=49$ times. By the end of the 14-hour test the initial batch of slurry had circulated $14 * 3600 / 25=$ 2,016 times. Conversely, at the end of the 12-hour ${ }^{\dagger}$ test for the pilot unit, with its longest residence time of 48 seconds, the slurry circulated only $12 * 3600 / 48=900$ times. Considering the high turnover rate of the slurry, the speed of the slurry, i.e., $3.7 \mathrm{~m} / \mathrm{s}$, and the pipe fittings and valves in the small-scale flow loop, the slurry in the small-scale unit does experience a considerable amount of shear. Many of the compounds that make up the slurry form strong oxide particles, which seem not to get any smaller than approximately 0.5 micron. In fact, it appears that particle breakup occurs mostly in the first few minutes of circulation and then remains fairly constant [8]. The conclusion here is that when large flat particles are broken down to smaller, less flat, particles the slurry filters better. Since the smaller particles measured were 3 to 20 times larger that the nominal pore rating of 0.1 micron, then the slurry becomes more filterable. That is, the flat particles are broken down so that they do not blanket the filter element. Unfortunately, this information only makes comparison of the two scales more difficult.

Another possible reason for differences in filter fluxes between the two units is wall shear. Figure 4 shows a cartoon of how a cross-flow filter works. As the slurry, and most of its liquor, travels through the center of a porous tube a filter cake builds up on the inside wall. The thickness of the cake is exaggerated in Fig. 4 for illustration, but it could eventually build up to only about the thickness on the order of $15 \mu \mathrm{m}$ [15].

An advantage of the cross-flow filter over a dead-end filter is that it does not need periodic changing because the moving, turbulent, slurry constantly shears the cake, keeping it at a reasonable thickness and a fairly constant filtering rate. Since the wall shear affects the cake formation on the porous wall, differing levels of shear will strongly influence the rate at which the slurry liquor can permeate through the filter, thus

\footnotetext{
${ }^{\dagger}$ Test times were different because while the filter flux at the small scale was higher than at the pilot scale, the pilot had more surface area [7 $\mathrm{x} 0.0912 \mathrm{~m}^{2}$ to $0.0182 \mathrm{~m}^{2}$, Table 1] and concentrated to $22 \mathrm{wt} \%$ instead of $19 \mathrm{wt} \%$.
}

resulting in different filtration rates. As was shown in Table 1, the small-scale filter has a smaller diameter and shorter porous tube length than the pilot-scale filter. However, Table 3 indicates that the operating parameters for the slurry axial velocity and transmembrane pressure were maintained the same at both scales. To see the wall-shear effect quantitatively a CFD model ${ }^{\sharp}$ was made for two simple slurries that represent the initial and the concentrated slurries of this test. Table 4 shows the parameters assumed for the small- and pilot-scale facilities. The slurry was assumed to be Newtonian and turbulent, i.e., Reynolds number greater than 2000.

The modeled slurries are very simple, but they are assumed to be sufficient to compare scale differences. Besides, the actual waste slurry at low solids concentration does indeed behave as a Newtonian solution. Moreover, as the solids concentration increases the actual waste becomes slightly thixotropic, i.e., shear thinning with a time dependent shear stress. This non-Newtonian effect is not strong and the waste closely behaves as a Bingham fluid, therefore; as long the slurry is flowing it still behaves like a Newtonian solution. While the Reynolds number in the larger diameter tube is $1 / 3^{\text {rd }}$ more than the smaller tube for the same slurry velocity, i.e.,

$\operatorname{Re}($ large $) / \operatorname{Re}($ small $)=$ large ID $/$ small ID $=0.0127 / 0.0095=1.33$,

the magnitude of both indicates turbulence, i.e., Re $>2000$.

Table 4. Parameters used in a wall shear CFD model

\begin{tabular}{|c|c|c|}
\hline Parameter for CFD Model & Initial Slurry & Final Slurry \\
\hline Flow Velocity $(\mathrm{m} / \mathrm{s})$ & 3.7 & 3.7 \\
\hline Slurry Density $\left(\mathrm{kg} / \mathrm{m}^{3}\right)$ & 1300 & 1500 \\
\hline Slurry Dynamic Viscosity (mPa-s) & 4 & 20 \\
\hline Filter Tube Inside Diameter $(\mathrm{m})$ & $0.0095 / 0.0127$ & $0.0095 / 0.0127$ \\
\hline Reynolds Number & $11400 / 15300$ & $2600 / 3500$ \\
\hline
\end{tabular}

Figure 7 shows the CFD results at a low undissolved solids concentration. Immediately obvious is the much higher wall shear for the small-scale tube. At $0.6 \mathrm{~m}$ the steady state wall shear is $24 \%$ higher for the small-scale tube. Further, it takes approximately $1 / 3^{\text {rd }}$ of the $0.6-\mathrm{m}$ span for the wall shear to come to steady state because of entrance effects. There is approximately the same entrance effect on the pilot-scale tube, but since it is 2.29 meters long the effect is much less on the overall wall shear. When taking into account the entrance effects, the wall shear for the $0.0095-\mathrm{m}$ inside-diameter (smallscale) tube is approximately $30 \%$ higher than the 0.0127 (pilotscale) tube.

As the slurry concentrates, the wall shear difference decreases. This decrease is seen in Fig. 8. When taking into

\footnotetext{
* The model was developed with Fluent ${ }^{\mathrm{TM}} 6.2$ segregated solver using a 3-D approach and a standard two-equation $\kappa-\varepsilon$ turbulence model. Approximately 200,000 non-uniform computational mesh points were used to capture the behavior in the boundary layer region.
} 
account the entrance effects, the wall shear for the small scale filter tube is approximately $20 \%$ higher than for the pilot-scale tube. However, after the filter cake builds up, the wall shear differences at the high concentrations may not be as significant. This reduction in significance is implied by the two permeate flux curves coming together above approximately $16 \mathrm{wt} \%$ in Fig. 6.

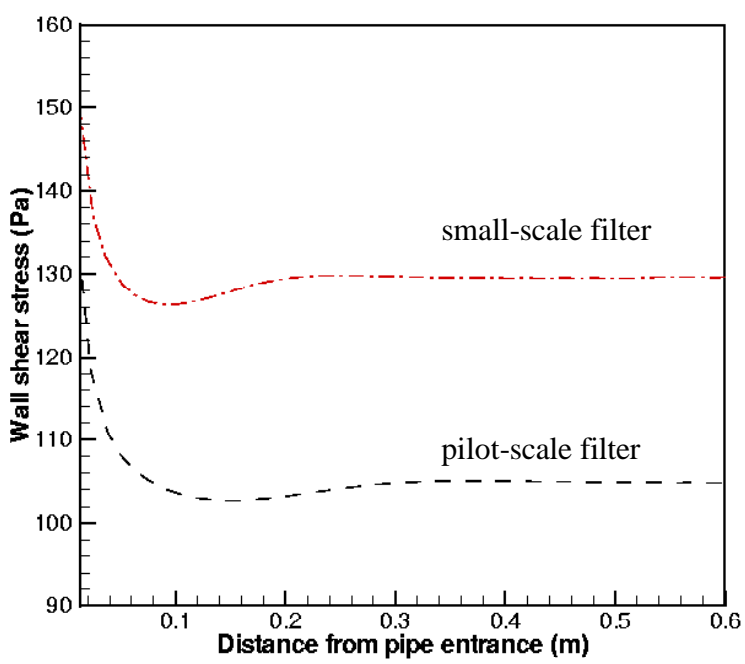

Figure 7. Wall shear comparison for two different tube IDs at a slurry velocity of $3.7 \mathrm{~m} / \mathrm{s}$, a slurry viscosity of $4 \mathrm{cP}$, and an undissolved solids loading from 1.2 to $1.4 \mathrm{wt} \%$ at $25^{\circ} \mathrm{C}$

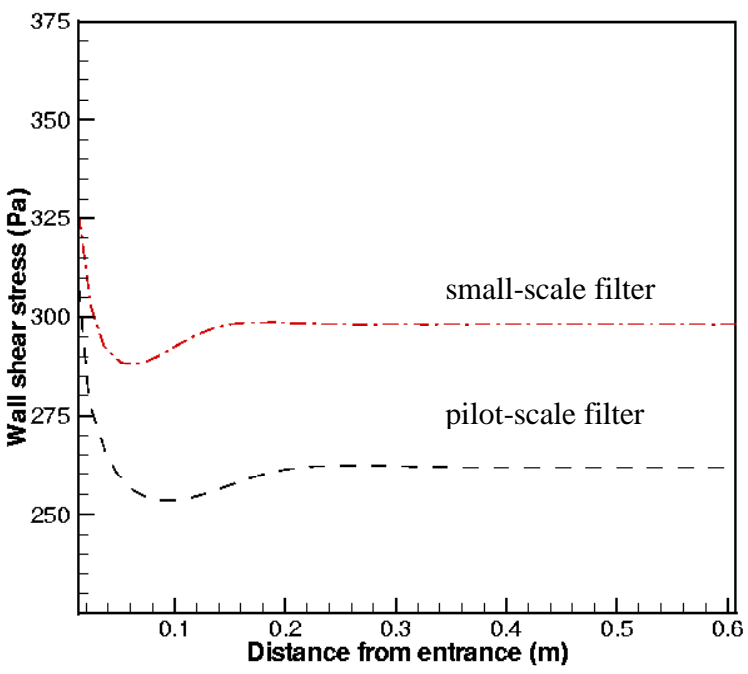

Figure 8. Wall shear comparison for two different tube IDs at a slurry velocity of $3.7 \mathrm{~m} / \mathrm{s}$, a slurry viscosity of $20 \mathrm{cP}$, and an undissolved solids loading from 19 to $22 \mathrm{wt} \%$ at $25^{\circ} \mathrm{C}$

In discussing crossflow filtration, Murkes and Carlsson [2: p. 3] state that it: "...is basically a cake-free method (or intended to be such). Its purpose is to prevent the formation of the cake. Particles deposited on the filter medium are swept away by the feed flow. The clean-keeping efficiency of the flowing liquid increases with its velocity. Thus, the particle and the solute concentration polarization (are) controlled by the flow velocity." To compare the small- and pilot-scale facilities the velocities were kept the same, however, due to differences in the porous-tube diameter and length, the larger, pilot-scale, channel had a lower wall shear, which is the mechanism that shears away the particles deposited on the filter medium. Shear stress is directly related to fluid velocity through Newton's law of viscosity, i.e.,

$$
\tau=\mu \mathrm{dv} / \mathrm{dy} \text { and at the wall } \tau_{\mathrm{wall}}=\mu[\mathrm{dv} / \mathrm{dy}]_{\mathrm{y}=0}
$$

where $\mathrm{v}$ is the local slurry velocity, $\mathrm{y}$ is the spatial coordinate perpendicular to the slurry flow, $\mu$ is the slurry dynamic viscosity, and $\tau$ is the local shear stress, Fig. 9. Murkes and Carlsson [2: pp. 18-21] show that the permeate flux is directly proportional to the filter cake permeability and inversely related to cake thickness. That is, as the cake forms under the local wall shear both parameters will be affected. Figure 9 shows a schematic of slurry flow in a porous tube with an established filter cake. As the diameter, D, gets smaller so does the turbulence level, because it is directly proportional to the Reynolds number, which is directly proportional to this dimension. However, as D becomes smaller the boundary layer, where wall shear stress occurs, becomes a larger portion of the flow area, which is proportional to the square of the diameter. Therefore, wall shear stress is larger for smaller flow channels as long as the velocity remains constant.

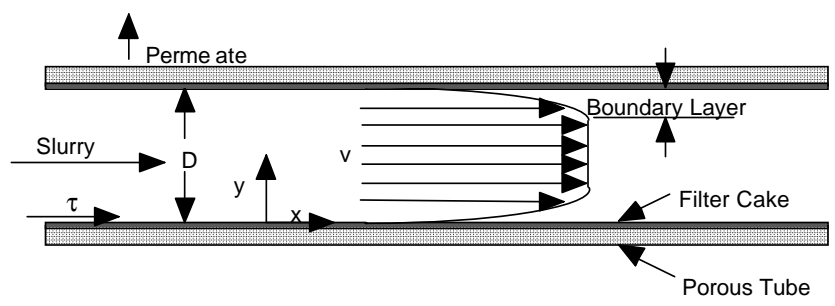

Figure 9. Slurry flow through a cross-flow ultrafiltration tube

Does the higher wall shear stress, and thus the higher "clean-keeping efficiency" of the small-scale filter shown in Figs. 7 and 8 cause it to have a higher permeate flux? The evidence seems to imply the affirmative. Is the initial $30 \%$ higher wall shear stress of the small scale enough to make its permeate flux approximately double that of the pilot scale? It is possible, but there is not enough quantitative data to show this fact. These organic-based waste slurries appear to be very sticky, that is, there seems to be sufficient inter-particle forces to make the solids cling to each other more than, for example, sand in water. These solids probably form some kind of a gellike cake on the filter surface, which does not lend itself to available analyses. However, the changing wall shear stress with scale must have an effect and possibly an effect large enough to cause the differing results obtained. 
A simple comparison check is shown in Fig. 10, which repeats the data displayed in Fig. 6 but with the pilot permeate flux increased by $30 \%$. Within measurement uncertainly the two data sets are still significantly different below $8 \mathrm{wt} \%$, but they are closer. Wall shear not only strips of filter cake during operation, but as the cake is developing the shearing action must play a primary role. Having filters at different scales and therefore at different amount of wall shear, will affect filter flux and probably in a very non-linear fashion. This means that linearly applying a 30\% correction, as in Fig. 10, is insufficient to capture the differences.

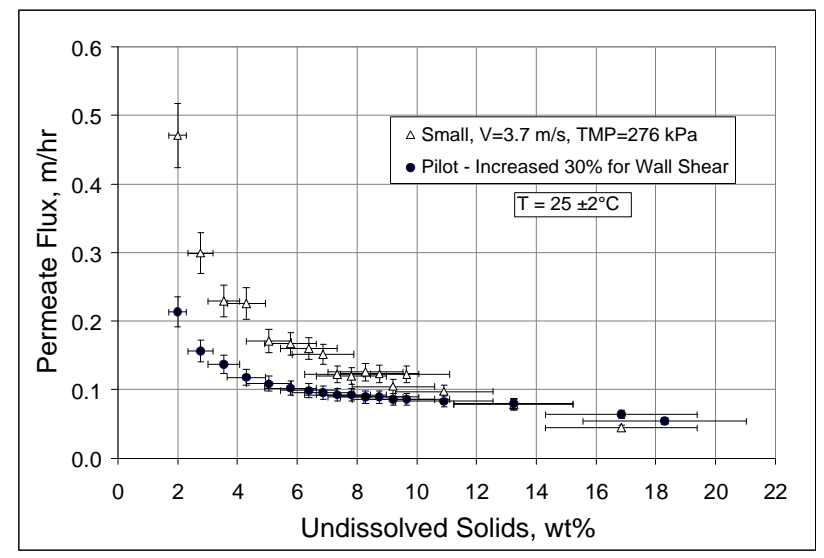

Figure 10. Small vs. pilot permeate flux increased by $30 \%$

\section{OTHER DIFFERENCES THAT MAY AFFECT FLUX}

Even if the particle morphology or wall shear differences could be accurately understood and taken into account, it may not be enough to show the differences between these two filter facilities. Other variations must exist and not easily quantifiable. Consider the differences in the two porous tubes used, or the pumps that circulated the slurries, or in the aging of waste simulants, even when the time difference is a matter of hours rather than days or months, etc.

Porosity - Two filters made to the same porosity may not give the same permeability. Both the small- and pilot-scale filters used 0.1 micron nominal porous tubes. However, each batch of sintered-metal tubes is different; even each segment is slightly different. The 0.1 micron is an average value. At this ultrafiltration pore size small differences in porosity may have significant permeability effects. For example, sintered-metal filter manufacturers state that just by changing the base filter material, e.g., steel vs. nickel, filters rated with the same nominal pore size, e.g., 0.1 micron, will exhibit significantly different permeabilities. This difference may be more related to how sintering process forms the porous substrate rather that the metal itself. Further, manufacturers continually attempt to improve their product that lead to differences in filter structure and thereby filtering performance. For thick wall metal porous tubes a pore size of 0.1 micron is state-of-the-art technology and is used for many purposes. As for this study, the porous tubes at both scales had the same pore size rating, but that does not always guarantee the porosity, pore size, etc. are exactly the same and at these sizes small difference can lead to large changes in operational performance.

Tube-Wall Thickness - A single segment of porous tubing may not be representative of a unit made of multiple segments. While the inside diameter of porous tubes with the same size specification should be close, due to the process of forming sintered metal around a very accurately ground mandrel, the outside diameter depends on the force of a flexible surface to maintain the metal particle under pressure. This was evident from the measurements made on the seven-tube pilot-scale tube assembly. Each of the seven tubes was made of four segments or 28 segments in all, Fig. 2. For this assembly a total of 100 measurements were made on those tubes to obtain a good average value of the tubes' diameter. The manufacturer's stated inside diameter was 0.01270 meter, but the received tubes had an average diameter of 0.01240 meter, with a maximum of 0.01245 meter and a minimum of 0.01232 meter. This 0.00013-meter variation is a tight tolerance and considered very good. However, the manufacturer's stated outside diameter was 0.0159 meter, but the actual average diameter measured to be 0.0166 meter, which ranged from 0.0171 meter to 0.0163 meter. This 0.0008 -meter variation is large and represents a $38 \%,\{[0.0008 /(0.0166-0.0124) / 2] \times 100 \%\}$, variation in the porous wall thickness! While the 7-tube pilotscale filter was made from 28 tube segments, the small-scale filter was comprised of a single tube segment, i.e., it represents only one of the pilot's segments. For this test the small-scale filter tube did have a different (smaller) nominal diameter then the pilot, but if it were of the same diameter, that single segment would not be expected to coincidentally match the average dimensions of a multi-segment pilot-tube assembly, nor the full-size plant assembly. This difference would lead differences in permeate flux.

As the filter cake builds up on the inside of the porous tube the differences in porosity and wall thickness become less evident because then the cake becomes the filtering medium and the largest source of pressure drop. However, the clean porous tube permeability is probably very important to how the filter cake is initially formed, which may persist for a significant amount of time until the cake is thick enough to make the two filters act the same.

Feed Pumps - As shown in Table 1, the pumps for the two facilities were different. The small-scale facility used a single air-driven progressive-cavity pump made by Oberdorfer. This pump had a stainless steel rotor, which was covered with a layer of hardened chrome. The rotor operated in a Buta-N stator, which has good resistance to caustic service but limited resistance to acid service, and moved the slurry in a piston-like fashion, through a helix-shaped cavity. Up to a threshold pressure this type of pump acts like a positive displacement 
pump, however, when the maximum pressure is reached (in this case it was approximately $620 \mathrm{kPa}$ ) the elastomer liner gives. At a steady-state operation of a slurry velocity of $3.7 \mathrm{~m} / \mathrm{s}$, the small-scale unit pump flow was $15.1 \mathrm{lpm}$. The pilot-scale facility used two centrifugal pumps in series and were made by Galigher. The impellers and housings were made of EPDM, which has good resistance to both acid and caustic services. The slurry flow was $193 \mathrm{lpm}$ to obtain a steady-state tube velocity of $3.7 \mathrm{~m} / \mathrm{s}$. With respect to shear, the progressivecavity pump imparted less than the centrifugal pumps, however, as seen in Table 3, and as already discussed, the small-scale slurry flow loop had a circulation rate an order of magnitude higher rate than the pilot loop due to the very small volume. Unfortunately, besides the high circulation rate, the high shear at the small-scale unit control valve may have negated any benefit of using a low-shear pump.

Time - The simulant used for this scale comparison was intentionally made as a single batch, which was then split into two volumes: one for the small-scale and one for the pilot-scale test facility. However, the filtration with the small-scale filter only began about 16 hours after the pilot-scale began. Table 3 shows some simulant differences for the two tests, e.g., the slightly larger particles for the simulant used with for the smallscale unit. Simulant analyses indicate that after 4 hours of mixing most chemical reactions are complete and the solution is predominantly stable. However, the small number of reactions may not have reached completion and may have affected filter performance. One example is that about $10 \%$ of the aluminum was still available as a undissolved solid when the pilot filtering began. When the small-scale filtering began 16 hours later most of that solid aluminum had dissolved into the aqueous. The presence of solid aluminum is known to inhibit filtration. The point here is that chemically the simulants were slightly different after only 16 hours of aging, which could have contributed to the differing results.

\section{CONCLUSION}

The small-scale filter operation works perfectly when used in the fashion that it was designed. That is, demonstrating filterability and in comparing the filter flux performance of two different slurries at the same scale. It is an effective means to fine tune a simulant so that it gives real waste filter performance. Unfortunately, there is evidence that small-scale data do not well represent filter performance at full size. Not only do small-scale data differ from large scale data, but it appears that they indicate more favorable filter performance. As such, their use may lead a plant design that does not meet production throughput expectations. When designing crossflow filter operations and full-scale testing is prohibitive, then, at a minimum, pilot-scale testing is necessary to obtain more accurate filter performance data.

\section{ACKNOWLEDGMENT}

This work was funded by U.S. Department of Energy and performed at the Savannah River National Laboratory, which is operated by the Washington Savannah River Company.

\section{REFERENCES}

[1] Rushton, A., A.S. Ward, and R.G. Holdrich, 2000, SolidLiquid Filtration and Separation Tech., $2^{\text {nd }}$ ed., Wiley-VCH.

[2] Murkes, J. and C.G. Carlsson, 1988, Crossflow Filtration: Theory and Practice, pub. John Wiley \& Sons.

[3] Bhave, R.R., 1997, "Cross-flow Filtration," found on page 273 in Fermentation and Biochemical Handbook: Principles, Process Design, and Equipment, $2^{\text {nd }}$ Ed., eds. H.C. Vogel, C.L. Todaro.

[4] Millward, H.B. and B.J. Bellhouse, 1996, "Scale-up of the Vortex Wave Microfilter using the Power Ration," J. Membrane Sci., 111, pp. 105-113.

[5] Gabler, R. and S. Messinger, 1986, "Scaling up membrane filter systems," CHEMTECH, 16(10), pp. 616-621.

[6] Shook, C.A. and M.C. Roco, 1991, Slurry Flow, Principle and Practice, pub. Butterworth-Heinemann.

[7] Nash, C.A., 1998, "Apparatus for Crossflow Filtration Testing of High Level Waste Samples," Advances in Filtration and Separation Technology, 12, from the $11^{\text {th }}$ Annual Technical Conference \& Exposition of the American Filtration \& Separation Society, pp. 472-478.

[8] Nash, C. A. and J. L. Siler. 1997, "Filtration of Nonradioactive Hanford Waste Simulants," USDOE Doc. No. SRTC-BNFL-016, Rev. 0.

[9] Zamecnik, J. R., Baich, M.A., Duignan, M.R., Nash, C.A. and Poirier, M. R., 2004, "Modeling the filtration of a Hanford Site tank 241-AN-102 waste sample at bench and pilot scales," USDOE Doc. No. WSRC-MS-2003-00756.

[10] Duignan, M.R., Nash, C.A., and Townson, P.S., 2001, "Pilot-scale cross-flow filtration for a radioactive waste simulant with high solids concentration and sodium molarity," $4^{\text {th }}$ Intern. Conf. Multiphase Flow, New Orleans, May 27-June 1.

[11] Duignan, M.R., Nash, C.A., and Townson, P.S., 2002, "Cross-flow filtration with a shear-thinning organic-based slurry," Exp. Therm. Fluid Sci., 26, pp. 683-691.

[12] Duignan, M. R., 2003,"Final Report: Pilot-scale cross-flow ultrafiltration test using a Hanford Site tank 241-AN-102 waste simulant," USDOE Doc. WSRC-TR-2003-00204.

[13] Eibling, R.E. and C.A. Nash, 2001, "Hanford waste simulants created to support the research and development on the River Protection Project - Waste Treatment Plant," USDOE Doc. WSRC-TR-2001-000338.

[14] Eibling, R.E., 2002, "Development of a Supernate Simulant for Hanford Tank 241-AY-102 Waste," USDOE Doc. WSRC-TR-2002-00040.

[15] Wakeman, R. J., 1994, "Visualization of cake formation in crossflow microfiltration," Trans. IChemE, Part A 72, pp. 530-540. 